\title{
Study on the Enneagram Model of Brand Personality
}

\author{
Zhiwei $X u^{1, a}$ and Jing Huang ${ }^{2, b}$ \\ ${ }^{1}$ Economics and Management School of Wuhan University, Wuhan, Hubei, China, 430072 \\ ${ }^{2}$ Economics and Management School of Wuhan University, Wuhan, Hubei, China, 430072 \\ a1258660910@qq.com, bhuangjing877@whu.edu.cn
}

Keywords: brand personality; enneagram; personality transformation

\begin{abstract}
Focusing on the study of brand personality, this paper combines enneagram and marketing, and forecasts the buying propensity and brand choice of people with different personalities using the enneagram. It shows through experimental verification and SPSS software analysis that Models H1a, $\mathrm{H} 2 \mathrm{a}, \mathrm{H} 2 \mathrm{~b}, \mathrm{H} 2 \mathrm{c}, \mathrm{H} 4 \mathrm{a}$, and $\mathrm{H} 4 \mathrm{~b}$ are established, which demonstrates the effect of the similarity between a brand and a personality on brand choice.
\end{abstract}

\section{Introduction}

With respect to the study of brand personality, there are relevant research methods proposed by various scholars. Among them, the most classical one is the systematic Brand Dimensions Scales (BDS) developed by Jennifer Aaker, the renowned American researcher in 1997 on the basis of the "Big Five" model of the western theory of personality together with the methodology of individual psychology dimensions and her study on well-known western brands. Compared with the relatively simple "Big Five" model, enneagram is of great research value and needs further study as a more detailed and profound uprising personality model. For example, the Brand Personality Dimensions and the attraction of brand to the individual derived from the Big Five Model only stress the similarity and the complementarity. The Big Five Model has a serious defect that it is too simple, because it has totally ignored the transformation of personality and made no study on the basic desire and fear of the individual. However, the enneagram has made incisive analysis of personality transformation as well as the individual's basic desire and fear, which shows greater reliability and validity than the Big Five Model. By using Jennifer Aaker's methodology in combination with the enneagram model and brand personality, we can open up a new research field from a different perspective[1].

Enneagram is a current thriving personality typology. Based on it, this paper points out the internal impetus driving the survival of human beings - desire and fear. Using it, we can decode the personality as well as make precise judgment and predictions on people's behaviors and motives with information revealed by their language, behavior, mood, expression, clothes and etc. This paper also attempts to forecast the buying propensity and brand choice of people with different personalities by combining the enneagram with marketing.

\section{Relevant Studies}

In the enneagram, personality types are classified into three categories according to individual basic desires and fears: feeling-centered, thinking-centered, and instinct-centered. And those three categories consist of three subtypes respectively. The feeling-centered category includes the Helper, the Achiever and the Individualist; the thinking-centered includes the Investigator, the Loyalist and the Enthusiast; and the instinct-centered contains the Challenger, the Peacemaker and the Reformer. Enneagram is a complex discipline, as every type of personality registers its own behavior pattern. If divided more specifically, each type can be classified into 9 classes in accordance with the level of health and stress. One personality can show completely opposite performance in various respects between people having high level and low level of heath, while the basic desires and fears are still consistent. In this paper, such consistence of personality which is not easy to be changed is used for the study of the relationship between brand/ business style and the personality being attracted[2]. 
Although human beings have endless desires and fears, the deepest basic fear and desire decides our personalities. For example, Type 2 the Helper's basic fear is being unloved and his basic desire is to feel love; Type 3 the Achiever's basic fear is being worthless and his basic desire is to feel valuable and make a name; Type 4 the Individualist's basic fear is having no identity or significance and his basic desire is to be uniquely themselves; Type 5 the Investigator's basic fear is being helpless or incompetent and his basic desire is to master more knowledge and skills; Type 6 the Loyalist's basic fear is insecurity and his basic desire is to have support and security; Type 7 the Enthusiast's basic fear is being trapped in pain or deprivation and his basic desire is to have all the pleasure and fresh things in the world; Type 8 the Challenger's basic fear is being dominated or controlled by the environment and his basic desire is to control and dominate the circumstances; Type 9 the Peacemaker's basic fear is being asked to change and his basic desire is to keep calm and peaceful; and Type 1 the Reformer's basic fear is corruptness, decadence and being bad and his basic desire is to be perfect.

Compared with the Big Five Model which argues that people's personality traits are static and constant, the enneagram model holds that personality traits are dynamic and can be transformed into other ones, which is a strong point of the enneagram. Each type of personality may show characteristics of other personalities regardless of in sound or unsound state.

Aaker put very simple the effect of people's personalities on brand choice[3]: similar or complementary to their personalities. This understanding is actually partial, because if a person likes a brand opposite to his personality, which represents he lacks this character, it must be a kind of complementarity according to the theory of the Big Five Model which defines personality traits as static and unchanged. But in light of the enneagram model, such choice made opposite to one's personality just shows one side of the personality transformation, as well as the traits appearing on each personality in certain stages. It does not mean lack and complementarity only. The basic model and characteristics of transformation are shown in Figure 1.
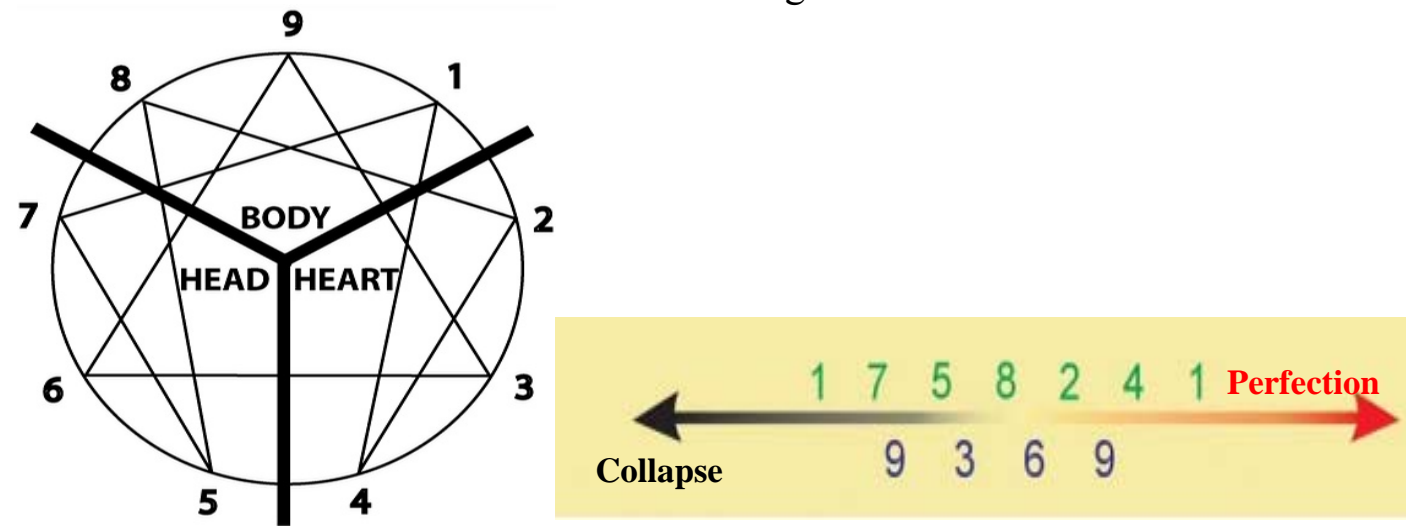

Fig. 1 The Enneagram Model and Characteristics of Transformation

Personality transformation can be interpreted practically as follows: when a person is in favorable circumstances with his psychology reaching a sound and balanced state, his personality will transform to another type and take on its most typical merits, which are complementary to his basic personality. From this angle the interpretation coincidences with Aaker's theory of "complementarity". However, when a person is in adversity with unsound and imbalanced mind, his personality will transform toward another direction and register intrinsic defects of another personality, which is definitely not complementary but does harm to his basic personality and is contradictory to his core values and desires. Such defects will lead people to "realize" the thing they fear most in their subconsciousness. That is, those defects will make the basic fear increasingly severe and pressing and the basic desire more illusory and unrealizable. Therefore, this paper tries to supplement Aaker's theory of "Similarity-Complementarity" with the theory of "Similarity-Complementarity-Contradiction". e.g. Type 1 the Reformer: when in favorable conditions with balanced mind, he will transform to Type 7 the Enthusiast and take on relevant merits (complementary). But when in adversity with imbalanced psychology, he will change to Type 4 the 
Individualist and take on relevant inherent weaknesses, such as strong jealousy and extreme depression (contradictory).

After making a general survey of traits shown by the enneagram of personality, we see that, if this model of personality is used to replace Jennifer Aaker's Big Five Model of personality, a complete different perspective is derived to interpret the behaviors relating to people's brand choices and Aaker's theory can be amended and supplemented. Later scholars have criticized Aaker and pointed out many problems existing in her theory: first, the Big Give Personality Model is over-simple, and can be seen as a very rough personality identifier, as well as has very bad performance in the practical application to clinical psychology, almost being useless; second, not all the scholars agree with her idea that personalities can be classified in accordance with the Big Five Model Dimensions; and finally, Aaker herself acknowledged that those five dimensions are rough and general as the features of many brands do not fall into those five dimensions. The point Asker ignored is that personality traits are not static and unchanged as she thought but dynamic and transformational. Thus she thought people chose brand either similar or complementary to their personalities. And therefore, this paper attempts to amend and supplement Asker's theory of "Similarity-Complementarity" using the theory of enneagram, especially the theory of personality transformation. Compared with the Big Five Model, the enneagram can provide a more specific analysis on enterprise personality. If it is applied to the enterprise products and brands, it may create better effects.

\section{Model Design}

Design of Brand Personality Dimension

Jennifer Aaker ever divided brand personality into five dimensions by using Big Five Personality Model, while this paper uses Aaker's classification method to divide the brand and products into nine dimensions according to Enneagram Model, with following characteristics respectively:

No.1 reformer brand: pay great attention to particulars, keep on improving and strive for perfection without any defect;

No.2 helper brand: show warmness and love to make people feel love, kindness, solicitude, tenderness and other affections;

No.3 achiever brand: lay stress on competitiveness with opponents and strive for excellence, efficiency and success;

No.4 individualist brand: place emphasis on the uniqueness with its own style, elegance and connotation;

No.5 investigator brand: pay more attention to the scientific and technological content and the global view to make people feel deep and sophisticated;

No.6 loyalist brand: have strong sense of crisis and pay more attention to safety, reliable quality and stability to earn people's trust;

No.7 enthusiast brand: pay more attention to happiness, feeling of freshness, creativity and enjoyment;

No.8 challenger brand: pay more attention to strength and powers to leave people en impression of overlord or king;

No.9 peacemaker brand: lay emphasis on harmony and compliance with rules and never change;

Design of Personality Transformation Model

The greatest difference between Enneagram Model and Big Five Model is personality transformation. The former holds that personality traits are not static or fixed; on the contrast, they are transformed to each other. Each personality has its own constant direction of transformation at pressured and relaxed conditions. There are many such examples, e.g. a warmhearted housewife who pays close attention to others usually becomes very high-handed and likes to control others when she is in adversity, and an artist who is wayward and rebels against orthodoxy at ordinary times will becomes very meticulous and strives for perfection when immersed in artistic creation. All of these are typical examples of personality transformation. 
So is it possible for a consumer to become the loyal fan of an enterprise's products because his/her personality matches with the enterprise's brand personality? According to previous studies, we admit the principle of like attracts like. Brand preference and selection is influenced by the personality. Based on this, this paper supposes nine assumptions according to the transformation mode of each personality in Enneagram Model:

No. 1 personality: reformer - transform to No.7 when at healthy mentality and to No.4 when at unhealthy mentality;

H1a: persons with type 1 personality has type 1's brand preference and selection (similarity theory)

H1b: some persons with type 1 personality has type 7's brand preference and selection (complementary theory)

H1c: some persons with type 1 personality has type 4's brand preference and selection (contradiction theory)

No. 2 personality: helper - transform to No.4 when at healthy mentality and to No.8 when at unhealthy mentality;

H2a: persons with type 2 personality has type 2's brand preference and selection (similarity theory)

H2b: some persons with type 2 personality has type 4's brand preference and selection (complementary theory)

H2c: some persons with type 2 personality has type 8's brand preference and selection (contradiction theory)

No. 3 personality: achiever - transform to No.6 when at healthy mentality and to No.9 when at unhealthy mentality;

H3a: persons with type 3 personality has type 3's brand preference and selection (similarity theory)

H3b: some persons with type 3 personality has type 6's brand preference and selection (complementary theory)

H3c: some persons with type 3 personality has type 9's brand preference and selection (contradiction theory)

No. 4 personality: individualist - transform to No.1 when at healthy mentality and to No. 2 when at unhealthy mentality;

H4a: persons with type 4 personality has type 4's brand preference and selection (similarity theory)

H4b: some persons with type 4 personality has type 1's brand preference and selection (complementary theory)

H4c: some persons with type 4 personality has type 2's brand preference and selection (contradiction theory)

No. 5 personality: investigator - transform to No.8 when at healthy mentality and to No.7 when at unhealthy mentality;

H5a: persons with type 5 personality has type 5's brand preference and selection (similarity theory)

H5b: some persons with type 5 personality has type 8's brand preference and selection (complementary theory)

H5c: some persons with type 5 personality has type 7's brand preference and selection (contradiction theory)

No. 6 personality: loyalist - transform to No.9 when at healthy mentality and to No.3 when at unhealthy mentality; theory)

H6a: persons with type 6 personality has type 6's brand preference and selection (similarity

H6b: some persons with type 6 personality has type 9's brand preference and selection (complementary theory)

H6c: some persons with type 6 personality has type 3's brand preference and selection (contradiction theory)

No. 7 personality: enthusiast - transform to No.5 when at healthy mentality and to No.1 when at unhealthy mentality;

H7a: persons with type 7 personality has type 7's brand preference and selection (similarity theory) 
H7b: some persons with type 7 personality has type 5's brand preference and selection (complementary theory)

H7c: some persons with type 7 personality has type 1's brand preference and selection (contradiction theory)

No. 8 personality: challenger - transform to No. 2 when at healthy mentality and to No.5 when at unhealthy mentality;

H8a: persons with type 8 personality has type 8 's brand preference and selection (similarity theory)

H8b: some persons with type 8 personality has type 2's brand preference and selection (complementary theory)

H8c: some persons with type 8 personality has type 5's brand preference and selection (contradiction theory)

No. 9 personality: peacemaker - transform to No.3 when at healthy mentality and to No. 6 when at unhealthy mentality;

H9a: persons with type 9 personality has type 9's brand preference and selection (similarity theory)

H9b: some persons with type 9 personality has type 3's brand preference and selection (complementary theory)

H9c: some persons with type 9 personality has type 6's brand preference and selection (contradiction theory)

\section{Verification Results of Model Statistics}

Setting of Environmental Parameters in Model Experiment

Experimental subjects are 338 university students in various majors, 147 males and 191 females, with average age: $20.1,22$ at maximum and 17 at minimum. Additional 5 marks will be offered to these students at time of final exam. This study is composed of two tests: A. Enneagram test and B. brand personality preference and selection test.

In Test A, there are several Enneagram versions available, including Riso-Hudson's 144-questions version, 108-questions version, 180-questions version, 135-questions version and 36-questions version. This paper used the most popular Riso-Hudson 144-questions version. Wagner (1983) ever conducted a test on its reliability and validity and found that this version had very high reliability and validity for all nine personality dimensions and absolutely could withstand the statistical test [4].

One week after Test A was finished, the brand selection behaviors questionnaire containing 36 questions was offered to 334 students who participated in Test A and 329 questionnaires were collected back one week later. This questionnaire, according to people's different brand preferences, raised a simple question, i.e. "I like a brand most because ", below which 9 brand personality dimensions were listed, 4 questions for each dimension, totally 36 questions, which are arranged randomly. Six-degree scale was used, respectively "absolutely consistent: 3 points", "more consistent: 2 points", "generally consistent: 1 point", "generally inconsistent: -1 point", "more inconsistent: -2 points", and "absolutely inconsistent: -3 points". Seven-degree scale is used more commonly. The reason that seven-degree scale is not used, i.e. not using the neutral option "uncertain: 0 point", is because neutral option tends to be selected more easily in traditional Chinese culture of comparative analysis. So we delete the neutral option. It can be seen that distinctively different personality traits are shown from factors $1 \sim 9$. The factors of brand preference are concluded according to each personality's most typical behavior patterns in Enneagram model[5].

Analysis of Model Experiment Results

According to the principles of statistics, 31 invalid questionnaires were excluded from the results of Test A by using SPSS software system. Among the rest 303 personality questionnaires, only 3 were found to have type 5 personality, so data about type 5 was too insufficient and we had to regrettably exclude type 5 personality from this test. The Crowns Bach $\alpha$ coefficient for the rest eight types of personalities was 0.81 for type $1,0.82$ for type $2,0.57$ for type $3,0.78$ for type $4,0.51$ for type $6,0.84$ for type 7, 0.84 for type 8 , and 0.79 for type 9 respectively. We had to exclude type 3 and type 6 from the assumption verification since the minimum acceptable range of Crowns Bach $\alpha$ 
coefficient is $0.65 \sim 0.78$. Thus, the valid types that can be verified include type 1 , type 2 , type 4 , type 7 , type 8 and type 9 .

Table 1 shows the data about the selections of type 1 personality.

Table 1 Descriptive Statistics

\begin{tabular}{|l|c|c|c|c|c|}
\hline & & & & $\begin{array}{c}\text { Mean } \\
\text { Value }\end{array}$ & $\begin{array}{c}\text { Standard } \\
\text { Deviation }\end{array}$ \\
\hline Factor 1 (Type 1's Brand Selection ehavior) & 33 & 8.00 & 12.00 & 9.0000 & 1.41421 \\
Factor 2 (Type 2's Brand Selection ehavior) & 33 & -2.00 & 5.00 & 3.2500 & 1.25831 \\
Factor 3 (Type 3's Brand Selection ehavior) & 33 & -1.00 & 5.00 & 2.2500 & 2.21736 \\
Factor 4 (Type 4's Brand Selection ehavior) & 33 & -6.00 & 11.00 & 2.5000 & 9.25563 \\
Factor 5 (Type 5's Brand Selection ehavior) & 33 & -2.00 & 8.00 & 5.0000 & 2.16025 \\
Factor 6 (Type 6's Brand Selection ehavior) & 33 & -2.00 & 3.00 & 1.0000 & 2.16025 \\
Factor 7 (Type 7's Brand Selection ehavior) & 33 & -8.00 & 9.00 & 1.5000 & 9.10350 \\
Factor 8 (Type 8's Brand Selection ehavior) & 33 & -2.00 & 8.00 & 1.7500 & 2.95743 \\
Factor 1 (Type 9's Brand Selection ehavior) & 33 & -1.00 & 6.00 & .5000 & 1.73205 \\
Valid N (Listwise) & 33 & & & & \\
\hline
\end{tabular}

It can be seen from above table that factor 1 (Type 1's Brand Selection Behavior) has the mean value of 9 (in the total of 12), which is the highest mean value among all factors, and the standard deviation is only 1.41421 . So the similarity theory of H1a: persons with type 1 personality have type 1 's brand preference and selection is tenable.

To verify the relevance, persons with type 1 personality are divided into two groups: A: those at state of psychological balance and B: those at state of psychological imbalance. Experimental results show that 14 persons belong to group $\mathrm{A}$ and 18 persons belong to Group $\mathrm{B}$, and one person has the same value for factors 4 and 7 and therefore is excluded. Then, analysis of factors is conducted for Group A and Group B respectively.

Before analysis of factors, KMO test and Bartlett's test of sphericity are conducted to judge whether data are suitable for the analysis. It can be seen from Tables 2 and 3 that KMO statistics are 0.661 and 0.861 for two groups, showing distinctive partial correlation, which proves that the two sets of data are suitable for analysis of factors. In addition, Bartlett's test of sphericity also rejects the null hypothesis of unit correlation matrix, $\mathrm{P}<0.001$, which also proves that they are suitable for analysis of factors. These two indicators show that the two sets of data are suitable for analysis of factors.

Table 2 KMO and Bartlett's Test for Group A

\begin{tabular}{|ll|l|}
\hline $\begin{array}{l}\text { Kaiser-Meyer-Olkin Measure } \\
\text { of Sampling Adequacy. }\end{array}$ & .661 \\
$\begin{array}{l}\text { Bartlett's Test of } \\
\text { Sphericity }\end{array}$ & $\begin{array}{l}\text { Approx. } \\
\text { Chi-Square }\end{array}$ & 124.942 \\
& df & 300 \\
& Sig. & .000 \\
\hline
\end{tabular}

Table 3 KMO and Bartlett's Test for Group B

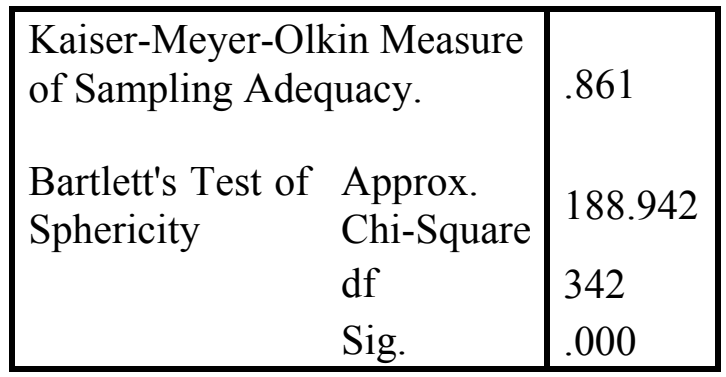

Table 4 Correlation Matrix for Group A

\begin{tabular}{|l|l|l|l|l|l|l|l|l|c|}
\hline & $\begin{array}{c}\text { Factor } \\
1\end{array}$ & $\begin{array}{c}\text { Factor } \\
2\end{array}$ & $\begin{array}{c}\text { Factor } \\
3\end{array}$ & $\begin{array}{c}\text { Factor } \\
4\end{array}$ & $\begin{array}{c}\text { Factor } \\
5\end{array}$ & $\begin{array}{c}\text { Factor } \\
6\end{array}$ & $\begin{array}{c}\text { Factor } \\
7\end{array}$ & $\begin{array}{c}\text { Factor } \\
8\end{array}$ & $\begin{array}{c}\text { Factor } \\
9\end{array}$ \\
\hline Factor 1 & 1 & & & & & & & & \\
\hline Factor 2 & 0.511 & 1 & & & & & & & \\
\hline Factor 3 & 0.323 & 0.021 & 1 & & & & & & \\
\hline Factor 4 & -0.410 & -0.412 & 0.342 & 1 & & & & & \\
\hline
\end{tabular}




\begin{tabular}{|l|l|l|l|l|l|l|l|l|l|}
\hline Factor 5 & -0.086 & -0.174 & -0.152 & 0.432 & 1 & & & & \\
\hline Factor 6 & -0.124 & 0.093 & 0.533 & 0.387 & 0.433 & 1 & & & \\
\hline Factor 7 & 0.732 & 0.41 & 0.373 & -0.233 & 0.562 & 0.421 & 1 & & \\
\hline Factor 8 & 0.34 & -0.51 & 0.503 & 0.321 & 0.321 & 0.212 & 0.322 & 1 & \\
\hline Factor 9 & 0.517 & 0.495 & -0.541 & 0.061 & 0.312 & 0.471 & -0.512 & 0.342 & 1 \\
\hline
\end{tabular}

Table 5 Correlation Matrix for Group B

\begin{tabular}{|l|l|l|l|l|l|l|l|l|l|}
\hline & $\begin{array}{c}\text { Factor } \\
1\end{array}$ & $\begin{array}{c}\text { Factor } \\
2\end{array}$ & $\begin{array}{c}\text { Factor } \\
3\end{array}$ & $\begin{array}{c}\text { Factor } \\
4\end{array}$ & $\begin{array}{c}\text { Factor } \\
5\end{array}$ & $\begin{array}{c}\text { Factor } \\
6\end{array}$ & $\begin{array}{c}\text { Factor } \\
7\end{array}$ & $\begin{array}{c}\text { Factor } \\
8\end{array}$ & $\begin{array}{c}\text { Factor } \\
9\end{array}$ \\
\hline Factor 1 & 1 & & & & & & & & \\
\hline Factor 2 & 0.546 & 1 & & & & & & & \\
\hline Factor 3 & 0.423 & 0.026 & 1 & & & & & & \\
\hline Factor 4 & 0.810 & -0.312 & 0.302 & 1 & & & & & \\
\hline Factor 5 & 0.176 & -0.263 & -0.252 & 0.477 & 1 & & & & \\
\hline Factor 6 & 0.484 & 0.093 & 0.433 & 0.487 & 0.133 & 1 & & & \\
\hline Factor 7 & -0.618 & 0.41 & 0.373 & -0.533 & 0.562 & 0.421 & 1 & & \\
\hline Factor 8 & 0.442 & -0.51 & 0.501 & 0.321 & 0.321 & 0.212 & 0.322 & 1 & \\
\hline Factor 9 & 0.523 & 0.487 & -0.612 & 0.077 & 0.212 & 0.321 & 0.512 & 0.489 & 1 \\
\hline
\end{tabular}

We can see that when type 1 are in "A" state (psychological balance), their brand preference has a high positive correlation with type7 $(r=0.732)$, and had no significant correlation between type 4's brand preference $(\mathrm{r}=-0.410)$; when type 1 are in "B" state( psychological imbalance), their brand preference and type 4's brand preference has a high positive correlation $(\mathrm{r}=0.810)$, and has a high negative correlation with type 7's brand preference $(\mathrm{r}=-0.618)$, so we can draw the conclusion: some persons with type 1 personality has type 7's brand preference and selection (complementary theory) And some persons with type 1 personality has type 4's brand preference and selection (contradiction theory). So H1b \& H1c are tenable.

Similarly, the experiment verifies that the models $\mathrm{H} 2 \mathrm{a}, \mathrm{H} 2 \mathrm{~b}$ and $\mathrm{H} 2 \mathrm{c}$ are tenable; $\mathrm{H} 3$ is excluded from the verification because of insufficient reliability; $\mathrm{H} 4 \mathrm{a}$ and $\mathrm{H} 4 \mathrm{~b}$ are tenable and $\mathrm{H} 4 \mathrm{c}$ is false; $\mathrm{H} 5$ is excluded due to persons are few and $\mathrm{H} 6$ is also excluded for failing the reliability test; $\mathrm{H} 7 \mathrm{a}$ and $\mathrm{H} 7 \mathrm{~b}$ are false and $\mathrm{H} 7 \mathrm{c}$ is tenable; $\mathrm{H} 8 \mathrm{a}$ and $\mathrm{H} 8 \mathrm{~b}$ are tenable and $\mathrm{H} 8 \mathrm{c}$ is false; $\mathrm{H} 9 \mathrm{a}, \mathrm{H} 9 \mathrm{~b}$ and $\mathrm{H} 9 \mathrm{c}$ are false.

\section{Conclusion}

This paper proposes the Enneagram model of brand personality, which coincides with Jennifer Aaker' study from the perspective of certain intents, since either Big Five Personality Model or Enneagram model proves that the similarity between brand personality and individual's personality has certain influence on brand selection. When an enterprise has its own die-hard fans and earns high trust from consumers, it is attributable to the matching of consumers' personality and the brand personality in a large extent.

This study first proves that Aaker's "similarity" theory is tenable by using anther personality model but also proves that the "complementary" theory shall be further improved. The initial intention of this study is to use the personality transformation theory of Enneagram model to introduce "complementary-contradiction" theories. Although study results show that such hypothesis is tenable, but the unexpected finding is that the influence of secondary personality on brand is far beyond the initial hypothesis of the study, while secondary personality almost has no obvious "complementation or contradiction" with core personality. This offers us a new research direction, and in future study, we can go deep into many more significant issues, e.g., the influence of secondary personality on brand selection or adding more factors of consumer behavior, such as price factor. The degree of consumer's preference for enterprise environment and view of value or the influence of 
personal brand on consumer behavior may also be considered. We can also change the research groups, such as employed persons, to verify the reliability and validity of this study.

\section{References}

[1] Lan Wu, Richard R. Klink, Jiansheng Guo: Creating Gender Brand Personality with Brand Names, American Marketing Association / Summer 2011.

[2] Gita Venkataramani Johar, Jaideep Sengupta, and Jennifer L Aaker: Two Roads to Updating Brand Personality Impressions: Trait Versus Evaluative Inferencing, Journal of Marketing Research Vol. XLII (November 2005),458-469.

[3] Jennifer L.Aaker:Dimensions of Brand Personality,JMR,Aug1997:34.3

[4] Rebecca A.Newgent,Patricia E.Parr and Kristin K.Higgims:The Riso-Hudson Enneagram Type Indicator:Estimates of Reliability and Validity, Measurement and Evaluation in Counseling and Development,Janany 2004 Volume 36.

[5] Manoj Thomas,Claire I. Tsai: Psychological Distance and Subjective Experience: How Distancing Reduces the Feeling of Difficulty. Journal of Consumer Research, Inc. Vol. 39 August 2012.

$\Delta$ uthor Introduction:

Zhiwei Xu, Doctor Candidate, Economics and Management School of Wuhan University, main rocearch directions: Brand Management, Marketing Psychology and Organization Theory.

1

${ }^{2}$ Jing Huang, Doctor in management, professor and doctoral advisor, Economics and Management School of Wuhan University, main research directions: Marketing, Brand Management and Organization Theory. 